\title{
Modeling of a Hydraulic Wind Power Transfer Utilizing a Proportional Valve
}

\author{
Majid Deldar, Afshin Izadian, Senior Member, IEEE, Masoud Vaezi, Sohel Anwar
}

\begin{abstract}
Hydraulic circuits can transfer remarkable amounts of energy in the desired direction without taking large space. To implement this technology for harvesting energy of wind appropriately, models of the system are required. Hydraulic wind power technology has the benefits of eliminating expensive and bulky variable ratio gearbox and its costly maintenance while enabling the integration of multiple wind turbines in a single generation unit. In this paper, the dynamics of different hydraulic elements are studied, nonlinearities are taken into account, pressure dynamics in different parts of the system are studied, and the motor load effects are considered. Based on these considerations, a novel non-linear state space representation of the system is introduced. Results of the mathematical model and the experimental data are compared to verify the proposed model. The comparison demonstrated that the mathematical model captures all major characteristics of the hydraulic circuit and can model the system behavior under different operating conditions.
\end{abstract}

Index Terms-Wind turbine, Hydraulic Wind Power Transfer, Mathematical Modeling.

\section{INTRODUCTION}

$\mathrm{R}$ ENEWABLE energies and specifically wind energy will have a greater portion in energy market than now in the coming decades[1-3]. Current wind turbines use gearboxes to provide energy for rotating the shaft which drives a generator. Because of relatively low wind speeds and large variations in wind speeds, wind turbines are designed to generate high torque at low speeds.

Hence to drive high speed generators, a variable ratio gearbox is needed. This adds a bulky, expensive, and hard to maintain piece of equipment in the drivetrain[4]. An alternative energy transfer technology, hydraulic power can be a promising avenue to wind power industries [5-8]. Some typical hydraulic applications are in construction, mining and material forming industries which need high power. These applications utilize the ability of hydraulic components to provide a huge amount of power in a compact space. However, utilization of hydraulic systems to harvest wind energy have not been well studied. Recently, emerging advanced hydraulic systems has enabled us to develop new generation of wind power plants.

Manuscript received December 2013, revised in April 2014. This research was conducted at the Energy Systems and Power Electronics Laboratory, the Purdue School of Engineering and Technology, Indianapolis.

M. Deldar, A. Izadian, M. Vaezi and S. Anwar are with the Purdue School of Engineering and Technology, Indianapolis, IN. 46202. Email: \{mdeldar\}, \{aizadian $\}^{*},\{$ mvaezi $\},\{$ soanwar\}@iupui.edu.

*Corresponding author.
Wind power is intermittent in nature. To reduce effects of the power fluctuation, different techniques can be applied. These techniques mainly consider the output power of the generator [9-11]. Several studies focus on the turbine/ generator control approaches to improve aerodynamic efficiency of the rotor and power quality of the generator [1215]. Utilization of hydraulics for power transmission requires studying flow and power control of the hydraulic circuits.

In this paper, an extended model of hydraulic wind power transfer system is introduced with more detailed analysis of pump and motor flows and torques. States of pressure in the system are investigated carefully to develop an extended state space model that can predict performance of the system more accurately. Based on this model, an accurate controller for an integrated multiple wind turbine system can be designed. Moreover, the effects of load torque on both primary and auxiliary motors are considered. In the new model, wind turbine is a prime mover for a hydraulic pump. The pump operates under working pressure of the system and provides flow to the primary and the auxiliary hydraulic motors. The primary motor drives a generator and the auxiliary motor stores excess energy in batteries through an electric generator or in hydraulic accumulators [16]. Previous studies [5, 8, 17] investigated simpler models of a hydraulic transfer system but in this paper a more realistic hydraulic system usable for wind turbine is proposed Nonlinear behavior of the proportional control valve is accounted for in the hydraulic circuitry. A mathematical model of the system is obtained and is compared with that of MATLAB SimHydraulics.

\section{WIND POWER TRANSFER SYSTEM CONFIGURATION}

Wind power is harvested using a high-torque low speed turbine. Intermittent wind speed introduces hydraulic flow fluctuations from the prime mover that eventually changes the electric power flow in the system[16].

Steady electric power generation requires a steady flow of pressurized hydraulic medium to the primary hydraulic motor. Proportional valves are used to regulate and control the hydraulic flow to manage the electric power generation.

Wind power drives a fixed displacement pump. The pump provides fluid under any working pressure of the system. The flow is passed to a proportional valve which distributes it to two hydraulic motors, the primary motor and the auxiliary motor. The primary motor is connected directly to the shaft of the generator while the auxiliary motor is driven by excess flow to store it as hydraulic energy in an accumulator or as electrical energy in batteries[16]. In reality, there are other hydraulic components designated for safety like the pressure 
relief valve that does not allow the system pressure to exceed the preset pressure and the check valve which ensures the flow only in the desired direction. Hydraulic components that affect dynamics of the circuit need to be models. These components are listed in the following:

\section{A. Pump}

A fixed positive displacement pump is used to flow high pressure fluid in the system. In a conventional hydraulic system, a variable displacement pump is more efficient since control of the displacement allows the adjustment of the flow to prevent the excess flow. Since an auxiliary motor can be used to capture the excess wind energy, using a fixed displacement is a smart because its price and maintenance costs are less than those of a variable displacement pump. Each pump has a theoretical displacement but based on its geometry and working pressure, a portion of the flow leaks back to the inlet port. The governing equation of a pump flow rate is described as follows [18, 19] :

$Q_{p}=D_{p} \omega_{p}-\frac{C_{S} D_{p}}{\mu} P_{p}$,

where, $Q_{p}$ is the actual delivered flow rate, $D_{p}, \omega_{p}$ and $P_{p}$ are the pump displacement, angular velocity and the differential pressure across the pump respectively. Cs and $\mu$ are the slippage coefficient and absolute viscosity. Cs is a constant term provided that the internal structure of a pump does not change [20]. Therefore, (1) can be re-written using the pump slippage coefficient $K_{p s}$ as follows:

$$
\begin{aligned}
K_{p s} & =\frac{C_{S} D_{p}}{\mu} \\
Q_{p} & =D_{p} \omega_{p}-K_{p s} P
\end{aligned} .
$$

The leakage is under influence of two mechanisms. The first mechanism is the laminar leakage due to pressure gradient in the clearance of the pump. The second mechanism is the flow loss due to compression and based on these mechanisms, different leakage models have been investigated in [3]. Laminar leakage exhibits a linear behavior which can also be experimentally proven [21-23]. This linear model has been frequently utilized in power transmission [19,24-26], wherein pumps and motors rotate continuously and their speeds are usually moderate to high.

In trajectory tracking application, the motor's shaft position and direction are controlled. The leakage specifically at very low velocity can exhibit nonlinear behavior so that more accurate leakage model can be used [2]

\section{B. Hydraulic Motor}

Since the flow to each motor is controlled by the proportional valve, both motors can operate with more efficient fixed displacement type hydraulic machines. This feature is especially important for the primary motor since it is connected to a synchronous generator that needs to be run at constant speed. The governing equation for the motor flow is similar to the pump's flow equation but with the motor leakage flow $K_{m s}$ as the additive term $[18,19]$ :
$Q_{m}=D_{m} \omega_{m}+K_{m s} P_{m}$,

where all of terms are similar to those of pump flow equation. $P_{m}$ is the pressure differential across the motor. Besides for each motor, the torque equation can be written based on driving torque and braking torques applied to a hydraulic motor. Additional resistive terms are not considered in the following formulation [10] because their values are typically much less than the viscous term [18, 19, 27]:

$I_{m} \frac{d \omega_{m}}{d t}=D_{m} P_{m}-C_{v} D_{m} \mu \omega_{m}-T_{l}$,

where, $I_{m}, P_{m}$ and $D_{m}$ are motor inertia, differential pressure across the motor and the motor displacement respectively. $C_{v}, \mu$ and $T_{\text {Load }}$ are viscous drag coefficient, absolute viscosity and load torque applied on the motor shaft respectively. A lumped coefficient can be used to replace the terms that multiplies to the motor velocity as the viscous damping coefficient and $B_{v}=C_{v} D \mu$. Re-writing the complete torque balance for both the primary motor (A) and the auxiliary motor (B), yields:

$$
\begin{aligned}
& I_{m A} \frac{d \omega_{m A}}{d t}=D_{m A} P_{m A}-B_{m A} \omega_{m A}-T_{l m A} \\
& I_{m B} \frac{d \omega_{m B}}{d t}=D_{m B} P_{m B}-B_{m B} \omega_{m B}-T_{l m B},
\end{aligned}
$$

where subscripts A and B refer to parameters of the primary motor and motor B refers to the auxiliary motor, respectively.

\section{Proportional Flow Control Valve}

To distribute the pressurized flow to the motors, a flow control valve can be implemented. From electrical point of view, the choice of flow control unit depends on the application and time constant of the system. For fast response systems such of hydraulic position control or precise trajectory tracking, a servo-valve can be used [28]. However, in the systems with large time constant such as wind turbines where a large rotor inertia in the range of mega kg.m2 can reach up to 10 second [29], a slow dynamic proportional valve can be used. The response time for typical proportional valve is in the range of 100-150 (ms) [30], which is significantly shorter than the wind turbine time constant.

A proportional valve can be utilized to control the flow at the motor inlets. At each outlet of the valve, the passing flow $[18,19]$ can be calculated as follows:

$Q=C_{D} A \sqrt{\frac{2 \Delta P}{\rho}}$,

where $C_{D}$ is the discharge coefficient, $A$ is the orifice area, $\Delta P$ is the pressure difference across the orifice and $\rho$ is the fluid density. The area of the orifice at each outlet is adjusted by placing a spool at the right opening portion. This action imposes resistance against the flow and builds up pressure at the inlet. The excess flow from the non-controlled outlet can be directed to an auxiliary motor to harvest energy. A 3-way proportional valve which is controlled by a solenoid can be utilized. The solenoid voltage and the valve main outlet flow are linearly proportional in a wide range of operation. 


$$
A_{M}=m V_{v}
$$

where $A_{M}$ is the passage area of the metering orifice, $V_{v}$ is voltage applied to the solenoid valve and $m$ is a constant. The valve is shown in Figure 1.

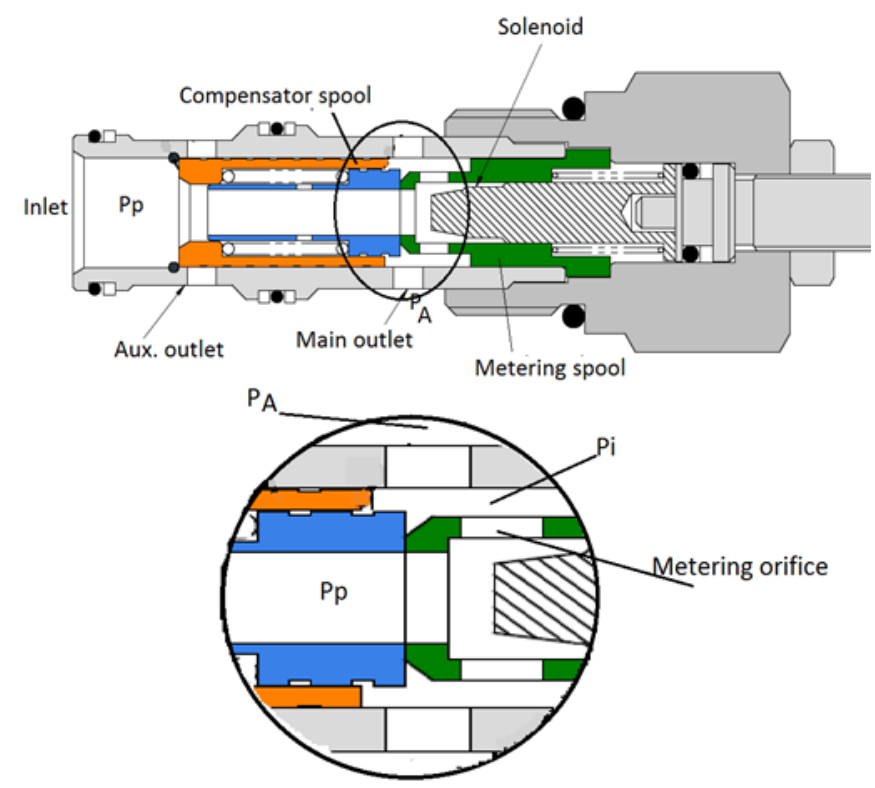

Fig. 1. Simplified schematic of a compensation mechanism within a flow control proportional valve.

The proportional valve is designed to control the flow rate. However, pressure variations across the valve, caused by the load change or the inlet flow change, affect the flow rate. The pressure compensation structures are designed in the valve to regulate the flow. Figure 2 demonstrates the pressure compensation structure. As the zoomed view of figure 1 shows, the area of the main outlet is adjusted automatically to match the pressure differences between the inlet and outlet $P_{p^{-}}$ $P_{i}$.

If the pressure differential decreases, the spring force shifts the piston to increase the main outlet area and vice versa. At pressure difference below the set point, the pre-compressed spring deactivates the system and the auxiliary port remains closed. When the inlet flow exceeds the set point, the outlet pressure builds up. At a preset value, it overcomes the spring force and the compensator spool is activated. Shift of the compensating spool, adjusts the intermediate pressure $P_{i}$ as shown in Figure 1.

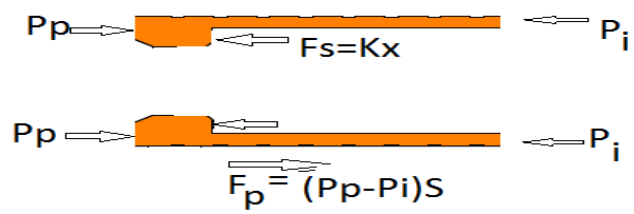

Fig. 2. Free body diagram of the compensator spool.

To determine the governing equations of flow rate at each outlet, the operation of the metering spool and the compensating spool are considered. The metering orifice, shown in Figure 1, is controlled by the metering spool. As well, the pressure differential between the inlet pressure, $P_{p}$, and the intermediate pressure, $P i$, determine the output flow rate from the metering orifice. Since the compensator spool adjusts the $P i$, this pressure differential is maintained regardless of the pressure fluctuation on the pump or motor side. The preset pressure differential is a constant parameter of the valve. The flow of the main outlet can be re-written as:

$Q_{M}=C_{D} A_{M} \sqrt{\frac{2 \Delta P_{r}}{\rho}}$,

where $Q_{M}$ is the main outlet flow and $\Delta P_{r}$ is the preset pressure differential. Since in (8) and (9), $m, C_{D}, \rho$ and $\Delta P_{r}$ are constant, (9) can be expressed as a linear function of the solenoid voltage and a constant gain as follows:

$Q_{p v-A}=Q_{M}=\left(C_{D} m \sqrt{\frac{2 \Delta P_{r}}{\rho}}\right) V_{v}=K_{v} V_{v}$,

where, $K_{v}$, is the flow gain at the main outlet, $V_{v}$ is the applied voltage at the valve solenoid. $K_{v}$ is considered a constant value obtained experimentally by measuring the main outlet flow at different applied voltages.

For the auxiliary valve outlet, the governing equation of flow is obtained through the compensation mechanism. In compensation mode, the compensator spool is shifted to open the passage area at the auxiliary outlet. The area is proportional to the compensator spool displacement as follows:

$A_{A}=n_{A} \Delta x$,

where $A_{A}$ is the passage area of the auxiliary port, $n_{A}$ is a constant and $\Delta x$ is the compensator spool displacement. The displacement is calculated from the steady state force balance of the compensator spool, shown in Figure 2, as follows:

$K_{S} \Delta x=S_{c}\left(P_{P}-P_{i}\right)$,

where $K_{S}$ is the spring stiffness, $\Delta x$ is the compression of the spring, $S_{c}$ is the area of the spool exposed to pressure, $\mathrm{Pp}$ is the inlet pressure and $P_{i}$ is the pressure at the auxiliary port (Fig.3.

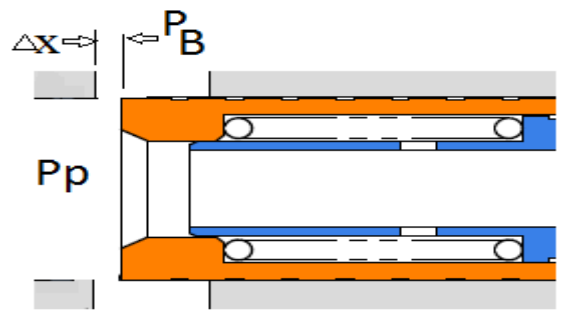

Fig. 3. Auxiliary outlet passage area.

The flow rate at the auxiliary port is obtained applying Equations 11 and 12 on Equation 7 as follows:

$$
\begin{aligned}
Q_{p v-B} & =Q_{A}=\left\{C_{D} n_{A} \frac{S_{c}}{K_{S}} \sqrt{\frac{2}{\rho}}\right\}\left(P_{p}-P_{i}\right) \sqrt{P_{p}-P_{B}} \\
& =K_{A}\left(P_{p}-P_{i}\right) \sqrt{P_{p}-P_{B}}
\end{aligned}
$$

where, $K_{A}$ is the flow gain of the auxiliary port and has constant value.

\section{Compressibility (Hose Dynamics)}

Although fluids are considered incompressible in macro scale, they have very small compressibility which determines the rate of pressure variation in any control volume. The fluid 
compressibility model gives the relationship between pressure changes and the amount of compressed flow in a control volume. This relationship is expressed as $[25,31]$ :

$\frac{d P}{d t}=\frac{\beta}{V} Q_{\text {Comp }}=\frac{\beta}{V}\left(Q_{\text {in }}-Q_{\text {out }}\right)$,

where $P$ is the pressure present at the hydraulic circuit segment, $\beta$ is the constant fluid bulk modulus, $Q_{\text {in }}$ and

$Q_{\text {out }}$ are the flows entering and exiting a control volume respectively.

In hydrostatic power transmission, the pressure is induced mainly by the torque load on the motor as expressed in (5) and (6) and effective control volumes are considered to determine pressure dynamics in different parts of the circuit. The boundary of a control volume used in Equation 14 can be defined within a hydraulic device or between different devices. For power transmission analysis, the rate of pressure variation at pump, motors and control valves are desired so that effective control volumes are those located in between them. The circuit and the boundary of control volumes are shown in Figure 4. Compressibility is written for each of these volumes, V1, V2 and V3. High pressure chambers of the pump and motors can be considered within these control volumes. The valve separates different control volumes since pressure drops across the valve orifices. Control volumes of the return lines as well as low pressure chambers of motors and the pumps are negligible since they have almost zero gauge pressure, they do not experience pressure variation.

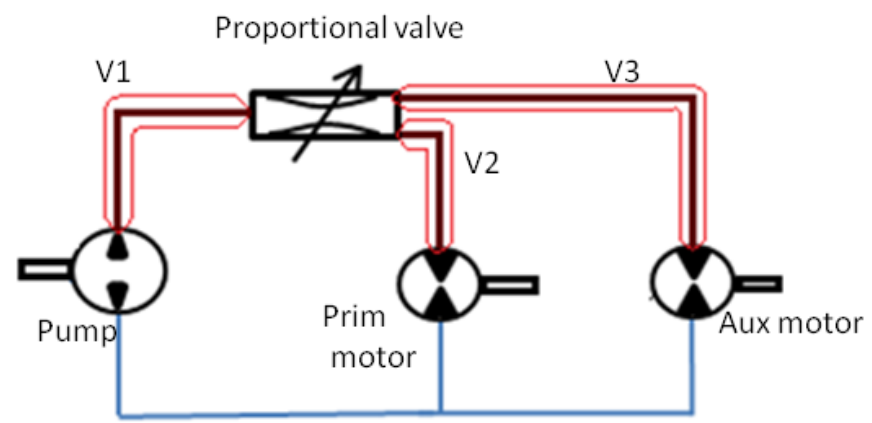

Fig. 4. Schematic of three piping parts of the circuit on which compressibility equations were used.

Therefore, the fluid compressibility for these control volumes can be written as follows:

$$
\begin{aligned}
& \frac{d P_{p}}{d t}=\frac{\beta}{V_{1}}\left(Q_{p}-Q_{P V . A}-Q_{P V . B}\right) \\
& \frac{d P_{m A}}{d t}=\frac{\beta}{V_{2}}\left(Q_{P V . A}-Q_{m A}\right) \\
& \frac{d P_{m B}}{d t}=\frac{\beta}{V_{3}}\left(Q_{P V . B}-Q_{m B}\right)
\end{aligned}
$$

where $Q_{P V . A}$ is the proportional valve flow rate exiting to motor A, $Q_{P V . B}$ is the proportional valve flow rate exiting to motor $\mathrm{B}, V_{(.)}$is the volume of fluid in the respective segment, and $P_{[32]}$ is the pressure of the respective segment.

\section{E. Other components:}

The hydraulic circuit, as mentioned earlier, has other safety components such as pressure relief valves and check valves which are not active in normal operations[33-35] In the hydraulic wind power transfer system configuration, considering the normal operation, the effect of these elements can be neglected.

The hydraulic wind power transfer system consists of three inputs: the pump angular velocity $\left(\omega_{\mathrm{p}}\right)$, the valve solenoid voltage $\left(V_{S}\right)$, and the load on motor A ( $\left.T_{m A}\right)$. The pump speed is a function of wind speed which can also be considered as a disturbance. The valve voltage is a control input to compensate for the pump velocity variations and the load torque fluctuations to achieve and maintain the desired generator speed.

\section{Hydraulic System State Space Model}

The models obtained at the component level can be used to express the overall system dynamics. Nonlinear presentation of the system model with energy storing state variables defined in vector $x$ can be obtained as follows:

$$
x=\left[\begin{array}{lllll}
P_{p} & P_{m A} & P_{m B} & \omega_{m A} & \omega_{m B}
\end{array}\right]^{T},
$$

where the state variables are pump pressure, the primary motor inlet pressure, the auxiliary motor inlet pressure, primary motor and auxiliary motor speed.

Considering $U=\left[\begin{array}{lll}\omega_{P} & V_{S o l} & T_{m A}\end{array}\right]^{T}$ as a vector with the pump speed, valve solenoid voltage and the load on motor A as inputs, the state space model of the system can be represented as:

$\dot{x}=f(x)+g(x) U$,

The functions $f(x)$ and $g(x)$ are found as follows:

$$
\begin{aligned}
& f(x)=\left\{\begin{array}{c}
\frac{\beta}{V_{1}}\left\{-K_{p} P_{p}-K_{A u x}\left(P_{p}-P i\right) \sqrt{P_{p}-P_{m B}}\right\} \\
\frac{\beta}{V_{2}}\left\{-D_{m A} \omega_{A}-K_{m A} P_{m A}\right\} \\
\frac{\beta}{V_{3}}\left\{K_{A u x}\left(P_{p}-P_{i}\right) \sqrt{P_{P}-P_{m B}}-D_{m B} \omega_{B}-K_{m B} P_{m B}\right\} \\
D_{m A} P_{m A}-B_{m A} \omega_{m A} \\
D_{m B} P_{m B}-B_{m B} \omega_{m B}-T_{l m B}
\end{array}\right\}, \\
& g(x)=\left[\begin{array}{ccc}
\frac{B}{V_{1}} D_{P} & \frac{\beta}{V_{1}}\left(-K_{V}\right) & 0 \\
0 & \frac{\beta}{V_{2}} K_{V} & 0 \\
0 & 0 & 0 \\
0 & 0 & -1 \\
0 & 0 & 0
\end{array}\right],
\end{aligned}
$$

\section{Model Validation: Simulation Results}

To investigate the mathematical model represented in the 
set of (16)-(19), experiments were run on a hydraulic set-up. The test setup is shown in Figure 5. Parameters of the system were obtained experimentally and listed in Table 1 . The pump speed is proportional to wind turbine speed; therefore, to evaluate the effect of wind turbine speed variation several pump speed sequences were applied to the set-up and the results were recorded. Similar pump speed sequences were applied to the mathematical model to compare the results. The point to point pressures of the system, motor speeds are compared and shown in this section. Figure 6 shows the pump speed sequence and comparison.

TABLE 1

Hydraulic Circuit PARAMETERS

\begin{tabular}{|c|c|c|c|}
\hline Symbol & QUANTITY & Value & Unit \\
\hline$D_{p}$ & Pump Displacement & 8.47 & $\mathrm{~cm}^{3} / \mathrm{rev}$ \\
\hline$D_{m A}$ & $\begin{array}{c}\text { Primary Motor } \\
\text { Displacement }\end{array}$ & 4.24 & $\mathrm{~cm}^{3} / \mathrm{rev}$ \\
\hline$D_{m B}$ & $\begin{array}{c}\text { Auxiliary Motor } \\
\text { Displacement }\end{array}$ & 8.47 & $\mathrm{~cm}^{3} / \mathrm{rev}$ \\
\hline$I_{m A}$ & Primary Motor Inertia & 0.0028 & $\mathrm{~kg} \cdot \mathrm{m}^{2}$ \\
\hline$I_{m B}$ & Auxiliary Motor Inertia & 0.0014 & kg. $m^{2}$ \\
\hline$B_{m A}$ & $\begin{array}{c}\text { Primary Motor viscous } \\
\text { Damping } \\
\end{array}$ & 0.0012 & N.m/rpm \\
\hline$B_{m B}$ & Auxiliary motor Damping & 0.0027 & N.m/rpm \\
\hline$K_{L, p}$ & Pump Leakage Coefficient & 20.08 & $\frac{\mathrm{cm}^{3} / \mathrm{min}}{\mathrm{bar}}$ \\
\hline$K_{L, m A}$ & $\begin{array}{c}\text { Primary Motor Leakage } \\
\text { Coefficient }\end{array}$ & 11.88 & $\frac{\mathrm{cm}^{3} / \mathrm{min}}{\mathrm{bar}}$ \\
\hline$K_{L, m B}$ & $\begin{array}{c}\text { Auxiliary Motor Leakage } \\
\text { Coefficient }\end{array}$ & 20.88 & $\mathrm{~cm}^{3} / \mathrm{bar}$ \\
\hline$\beta$ & Fluid Bulk Modulus & 12670 & bar \\
\hline$\rho$ & Fluid Density & 844 & $\mathrm{~kg} / \mathrm{m}^{3}$ \\
\hline$v$ & Fluid Viscosity & 32 & $\mathrm{cSt}$ \\
\hline$M_{A}$ & $\begin{array}{l}\text { Load torque on primary } \\
\text { motor }\end{array}$ & 1.4 & N.m \\
\hline$M_{B}$ & $\begin{array}{l}\text { Load torque on auxiliary } \\
\text { motor }\end{array}$ & 0 & N.m \\
\hline$\Delta P_{\text {reg }}$ & Preset pressure differential & 8.5 & bar \\
\hline Kspg & Spring stiffness & 44 & $\mathrm{~N} / \mathrm{cm}$ \\
\hline$A_{\text {Main }}$ & Max metering orifice area & 7.8 & $\mathrm{~mm}^{2}$ \\
\hline Vsol & Valve voltage & 2.9 & volt \\
\hline
\end{tabular}

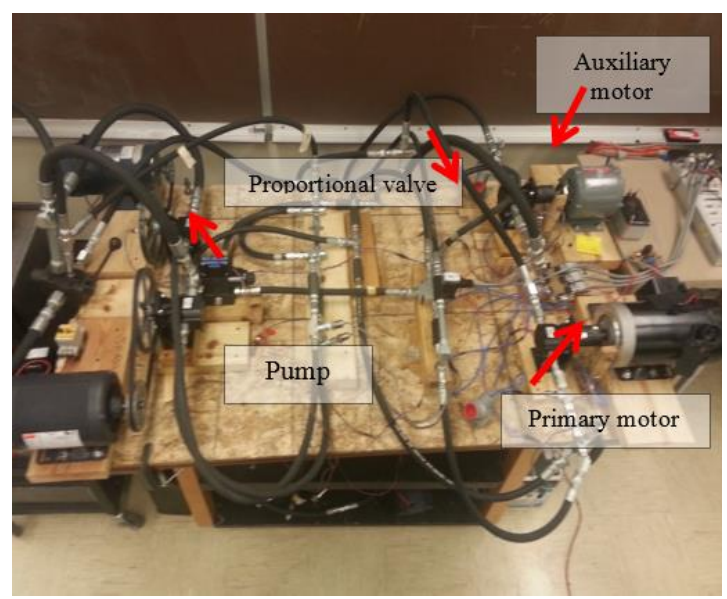

Fig. 5. View of the hydraulic prototype in the ESPEL research laboratory, Purdue School of Engineering and Technology, Indianapolis.

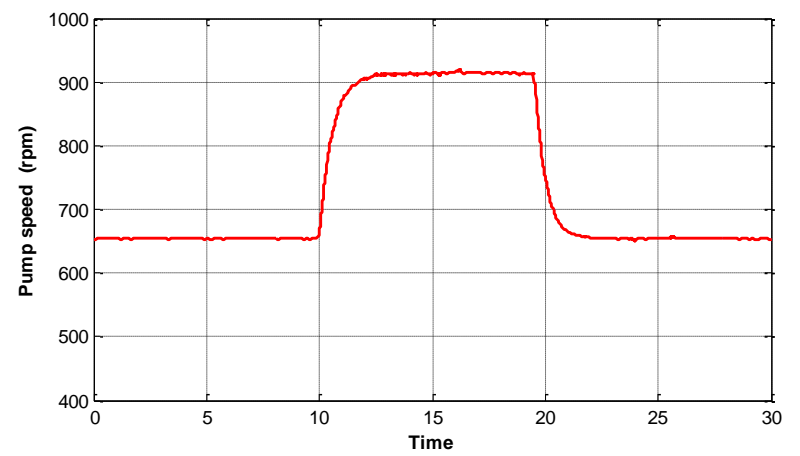

Figure 6. Pump velocity steps applied in experiment and mathematical model.

Pump speed was initially $655 \mathrm{rpm}$, a $40 \%$ step change was applied to reach speed of $915 \mathrm{rpm}$ and a return to the initial value was programmed.

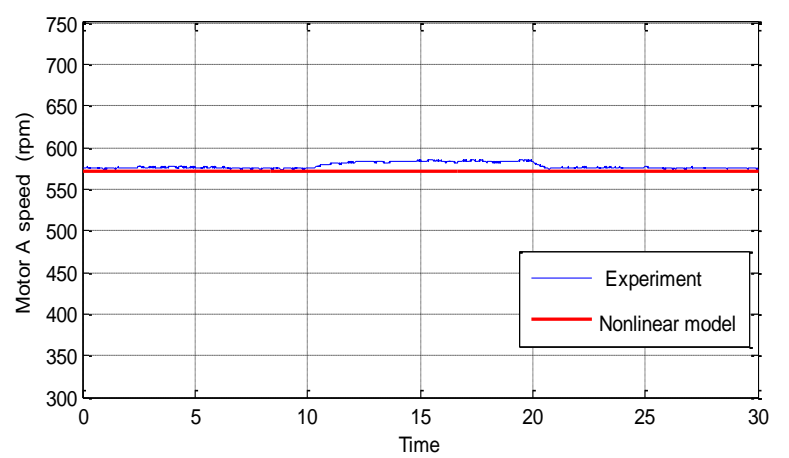

Fig. 7. Primary motor velocity profile as a result of wind speed step changes.

As Figure 7 demonstrates, the primary motor speed is maintained constant regardless of the pump speed. Since the valve voltage is constant, the motor speed is maintained constant in spite of a large pump speed increase. This follows the governing equation illustrated in (10). Slight motor speed variation of less than $2 \%$ was observed from experimental data during high pump speed.

Variation of auxiliary motor speed is illustrated in Figure 8. Since the primary motor flow is kept constant, the excess flow at the high pump speed is directed to the auxiliary motor and caused a speed increase from $250 \mathrm{rpm}$ to $500 \mathrm{rpm}$.

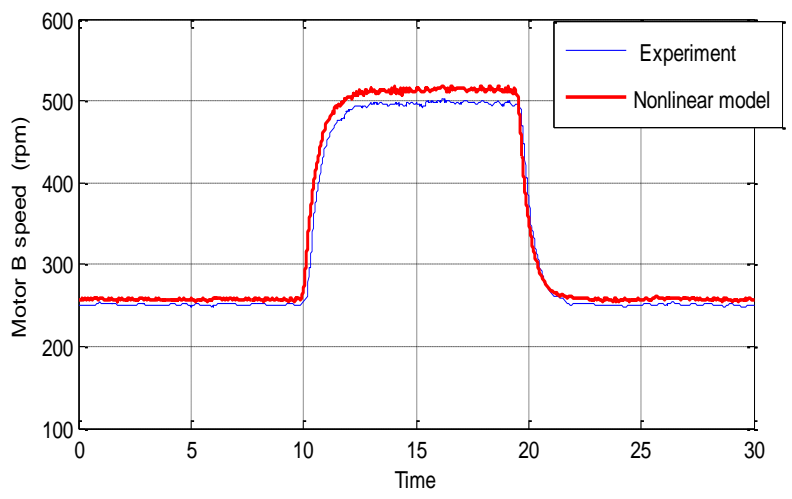

Fig. 8. Auxiliary motor velocity profile as a result of wind speed step changes.

Figure 9 illustrates the pump pressure when the speed change was enforced. It can be observed that at the high pump speed, the pump pressure increased less than $4 \%$. The reason 
for this pressure increase can be found in the governing equation (6). As the auxiliary flow and consequently the auxiliary motor speed was increased, the viscous drag on motor (B) also increased and caused a pressure increase.

As the primary motor (A) load and speed were kept constant, the pressure of this motor is remained constant. This is shown in Figure 10. Auxiliary motor (B) experienced a viscous drag increase for the same pump motor speed sequence; hence a pressure increase was observed. This is shown on Figure 11.

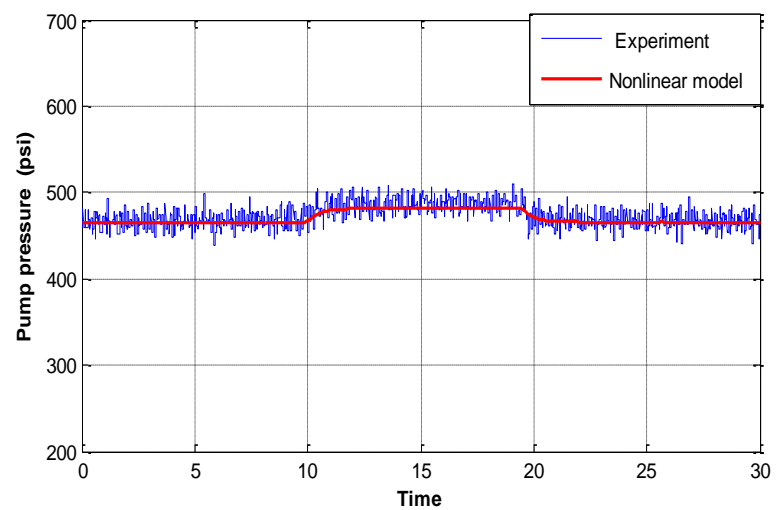

Fig. 9. Pump outlet pressure profile as a result of wind speed step changes.

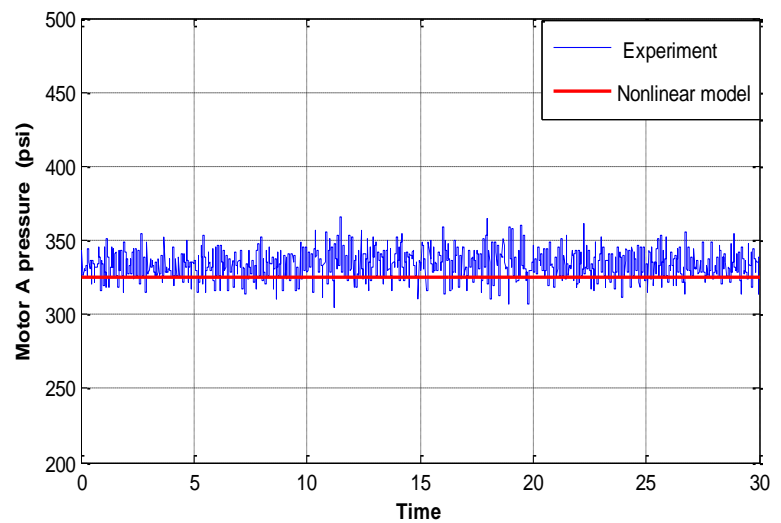

Fig. 10. Primary motor pressure profile as a result of wind speed step changes.

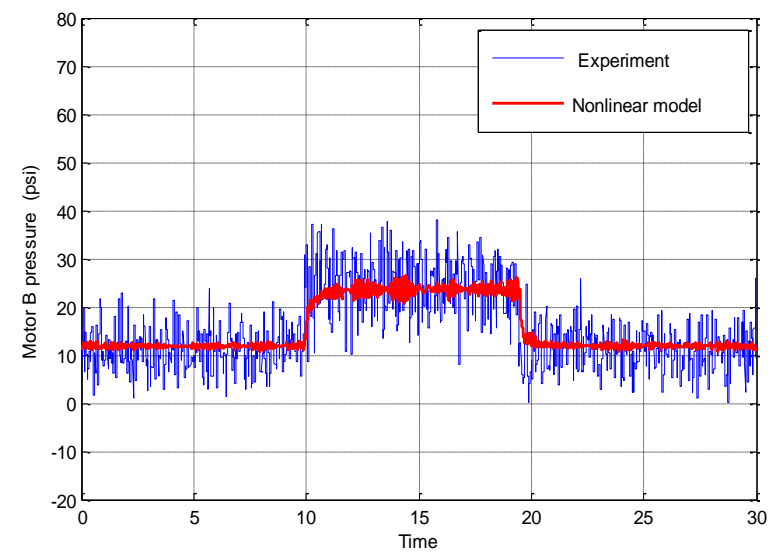

Fig. 11. Auxiliary motor pressure profile as a result wind speed step changes.
Figure 12 illustrates differences between recorded speeds of the motors from experimental setup and that of the simulation. The primary motor speed experiment showed a $2 \%$ deviation from simulation results. This validates the mathematical modeling proposed in this paper. At the auxiliary motor (B), less than $4 \%$ deviation between the experiment and simulation results were observed at the steady state operation. A higher deviation of $12 \%$ was observed during transients. It can be concluded that the actual damping of the hydraulic circuit was higher than that of the model. Flexibility of hose walls and check valves were not considered in the model which contributed in the deviation.

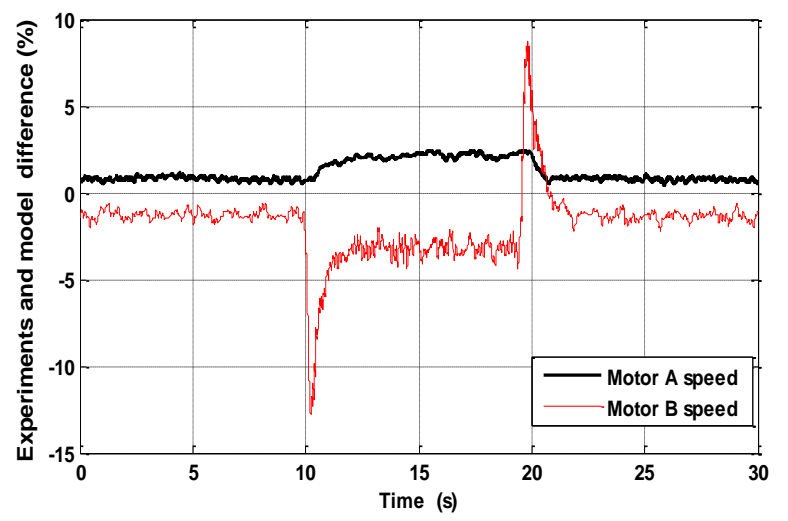

Fig. 12 Difference between recorded motors speed from experiments and the model simulation (percentage).

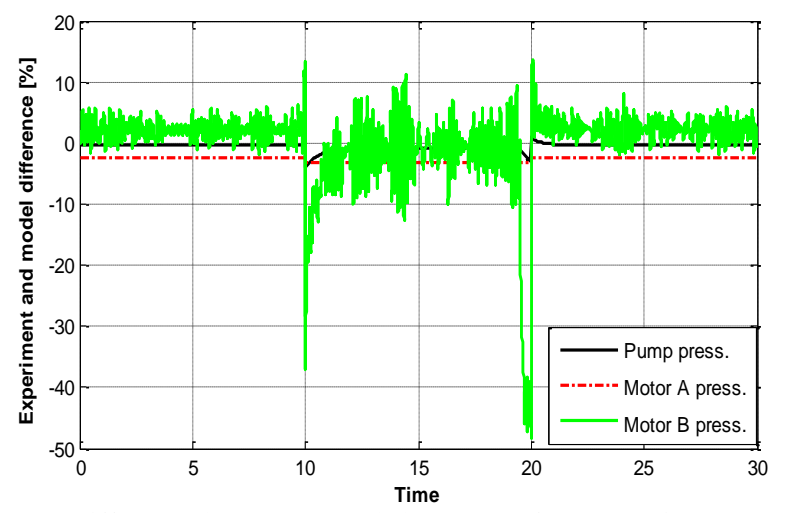

Fig. 13 Difference between recorded pressure from experiments and the model simulation (percentage).

As demonstrated in Figure 13, the pump and the primary motor pressures of the model matched well with that of the experiments. At the auxiliary motor, since no load was applied, only viscous drag induced the pressure. Therefore, a pressure increase in the range of 10-25 psi was recorded while the steady state pressure was in the same range. The pressure sensors of the set-up have an accuracy of at this range. This resulted in higher pressure differences between experiments and the simulation during transients. Overall, the experimental results and simulations matched well and the mathematical model accuracies were validated by experimental data. 


\section{CONCLUSION}

A novel non-linear model of hydrostatic wind power transfer system was developed in this paper. The nonlinear model significantly was enhanced by considering three pressures in the hydraulic circuit as system state variables. The structure of pressure compensated valve and the governing equations were obtained and validated by experimental results. Results of the mathematical model and the experimental data are compared to verify of the proposed model. Overall, the model behavior of pressure and velocity of hydraulic motors were in close agreement with those observed in the experiment. The comparison demonstrated that the mathematical model captures all major characteristics of the hydraulic circuit and can model the system behavior under different operating conditions.

\section{REFERENCES}

[1] A. V. Da Rosa, Fundamentals of renewable energy processes: Academic Press, 2005.

[2] J. Yao, Z. Jiao, D. Ma, and L. Yan, "High-accuracy tracking control of hydraulic rotary actuators with modeling uncertainties," IEEE/ASME Transactions on Mechatronics, vol. 19, no. 2, pp. 633-641, Apr. 2014..

[3] K.-E. Rydberg, Efficiencies for variable hydraulic pumps and motors-Efficiencies for variable hydraulic pumps and motors. Sweden: Linköpings University, Department of Management and Engineering, 2009.

[4] A. Ragheb and M. Ragheb, "Wind turbine gearbox technologies," in Nuclear \& Renewable Energy Conference (INREC), 2010 1st International, 2010, pp. 1-8.

[5] S. Hamzehlouia and A. Izadian, "Nonlinear state space model of a hydraulic wind power transfer," in IECON 2012-38th Annual Conference on IEEE Industrial Electronics Society, 2012, pp. 1098-1103.

[6] S. Hamzehlouia and A. Izadian, "Adaptive speed regulation of gearless wind energy transfer systems," in IECON 2012-38th Annual Conference on IEEE Industrial Electronics Society, 2012, pp. 2162-2167.

[7] S. Hamzehlouia, A. Izadian, A. Pusha, and S. Anwar, "Controls of hydraulic wind power transfer," in IECON 2011-37th Annual Conference on IEEE Industrial Electronics Society, 2011, pp. 2475-2480.

[8] A. Izadian, S. Hamzehlouia, M. Deldar, and S. Anwar, "A Hydraulic Wind Power Transfer System: Operation and Modeling," Sustainable Energy, IEEE Transactions.

[9] C. Carrillo, A. Feijoo, J. Cidras, and J. Gonzalez, "Power fluctuations in an isolated wind plant," Energy Conversion, IEEE Transactions on, vol. 19, pp. 217-221, 2004.

[10] S. Gao and N. Zhang, "A review of different methodologies for solving the problem of wind power's fluctuation," in Sustainable Power Generation and Supply, 2009. SUPERGEN'09. International Conference on, 2009, pp. 1-5.

[11] P. Sorensen, N. A. Cutululis, A. Vigueras-Rodríguez, L. E. Jensen, J. Hjerrild, M. H. Donovan, and H. Madsen, "Power fluctuations from large wind farms," Power Systems, IEEE Transactions on, vol. 22, pp. 958-965, 2007.

[12] F. D. Bianchi, H. De Battista, and R. J. Mantz, Wind turbine control systems: principles, modelling and gain scheduling design: Springer, 2006.

[13] D. Bourlis, "A complete control scheme for variable speed stall regulated wind turbines," Fundamental and Advanced Topics in Wind Power, pp. 309-339, 2011.
[14] B. Neammanee, S. Sirisumrannukul, and S. Chatratana, "Control Strategies for Variable-speed Fixed-pitch Wind Turbines," ed: Department of Electrical Engineeering, Faculty of Engineering, King Mongkut's University of Technology North Bangkok, National Science and Technology Development Agency, Thailand.

[15] J. S. Thongam and M. Ouhrouche, "MPPT control methods in wind energy conversion systems," Fundamental and Advanced Topics in Wind Power, pp. 339-360, 2011.

[16] A. Izadian, "Central Wind Turbine Power Generation," ed: Google Patents, 2010.

[17] A. Pusha, A. Izadian, S. Hamzehlouia, N. Girrens, and S. Anwar, "Modeling of gearless wind power transfer," in IECON 2011-37th Annual Conference on IEEE Industrial Electronics Society, 2011, pp. 3176-3179.

[18] E. Fitch and I. Hong, "Hydraulic component design and selection. BarDyne," ed: Inc, 2001.

[19] H. E. Merritt, Hydraulic control systems: J. Wiley, 1967.

[20] J. F. Blackburn, Fluid power control: Mit Press, 1969.

[21] B. Rexroth, "Fixed Displacement Pump A4FO," ed, 2013.

[22] E. Vickers, "Hydrokraft Transmission Piston Pumps," in Technical catalogu, ed, 2013.

[23] Parker, "Denison GOLD CUP® Product Catalog Piston Pumps \& Motors," in HY28-2667-01/GC/NA,EU, ed, 2010.

[24] E. C. Fitch, Hydraulic component design and selection: Bardyne. Incorporated, 2004.

[25] N. Manring, Hydraulic control systems: John Wiley \& Sons Incorporated, 2005.

[26] J. Schmitz, M. Vukovic, and H. Murrenhoff, "Hydrostatic Transmission for Wind Turbines: An Old Concept, New Dynamics," in ASME/BATH 2013 Symposium on Fluid Power and Motion Control, 2013, pp. V001T01A029-V001T01A029.

[27] M. Gorbeshko, "Development of Mathematical Models for The Hydraulic Machinery of Systems Controlling the Moving Components," Hydrotechnical Construction, vol. 3, 1997.

[28] J. Yao, J. Xia, and D. Ma, "Extended-state-observer-based output feedback nonlinear robust control of hydraulic systems with backstepping," IEEE Transactions on Industrial Electronics, vol.61, no. 11, pp. 6285-6293, Nov. 2014.

[29] Á. G. Rodríguez, A. G. Rodríguez, and M. B. Payán, "Estimating wind turbines mechanical constants," in Proc. Int. Conf. Renewable Energies and Power Quality (ICREPQ'07), 2007, pp. 27-30.

[30] B. Rexroth, "Proportional flow control valve," ed, 2014.

[31] A. V. Akkaya, "Effect of bulk modulus on performance of a hydrostatic transmission control system," Sadhana, vol. 31, pp. 543-556, 2006.

[32] J. Ivantysyn and M. Ivantysynova, Hydrostatic pumps and motors: principles, design, performance, modelling, analysis, control and testing: Akad. Books Internat., 2001.

[33] Y. Hou, L. Li, P. He, Y. Zhang, L. Chen, and C. Center, "Shock Absorber Modeling and Simulation Based on Modelica," in Proceedings of the 8th International Modelica Conference, 2011, pp. 843-846.

[34] G. Licskó, A. Champneys, and C. Hós, "Dynamical analysis of a hydraulic pressure relief valve," in Proceedings of the World Congress on Engineering, 2009.

[35] Z. Pandula and G. Halász, "Dynamic model for simulation of check valves in pipe systems," Periodica Polytechnica Mechanical Engineering, vol. 46, pp. 91-100, 2002. 


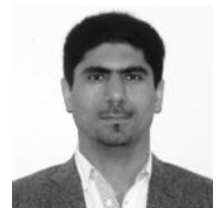

Majid Deldar was born in Esfahan, Iran in 1979. He received his MS in Mechanical Engineering from Amir Kabir University of Technology, Tehran, Iran in 2004. He is currently a PhD student at Energy Systems and Power Electronics Laboratory (ESPEL), Purdue School of Engineering and Technology at Indianapolis, IUPUI. His research interests are wind turbine technologies and hydrostatic transmission.

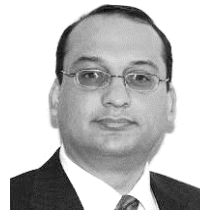

Afshin Izadian, (SM. 2004, M. 2009, SM 2010) received his $\mathrm{MS}$ in Electrical Engineering from Iran University of Science and Technology in 2002, and his $\mathrm{PhD}$ in Electrical Engineering from West Virginia University in 2008. He was a postdoctoral researcher at University of California Los Angeles in 2009. As an Assistant Professor he joined the Purdue School of Engineering and Technology, Indianapolis, IUPUI in 2009. $\mathrm{He}$ is the founder and director of the Energy Systems and Power Electronics Laboratory (ESPEL) at IUPUI. His research interests are Application of Controls in Energy Systems, Energy Conversion, Power Electronics and Electric Power Systems. He is a Senior Member of IEEE and a lifetime member of Etta Kappa $\mathrm{Nu}(\mathrm{HKN})$ and Tau Beta Pi (TBP).

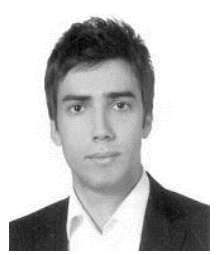

Masoud Vaezi received the B.Sc. degree in Mechanical Engineering from K. N. Toosi University of Technology, Tehran, Iran, in 2012. $\mathrm{He}$ received the M.Sc. degree in Mechanical Engineering from Purdue School of Engineering and Technology, Indianapolis, USA, in 2014. He was a research assistant at the Energy Systems and Power Electronics Laboratory, ESPEL. His areas of interest are modeling, simulation, and control of integrated systems.

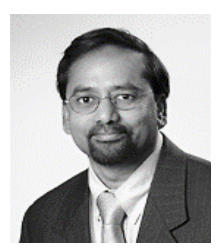

Sohel Anwar is currently Associate Professor at Purdue School of Engineering and Technology Indianapolis, in the department of Mechanical Engineering. His is also the chair of graduate education and research committee and director of Mechatronics Research Laboratory. $\mathrm{He}$ is a Member of the ASME. He is an Associate Editor of the IEEE Transactions on Vehicular Technology. His research interests include Wind Turbine Modelling and Control, Fault Diagnosis of Traction Batteries, Sensor Development, and Automotive Control Systems 